Article DOI: https://doi.org/10.35219/im.2018.2.01

\title{
A PARALLEL BETWEEN THE SIX METHODS OF MEASURING VIBRATIONS TRANSMITTED TO THE WHOLE BODY
}

\author{
Fiz. Drd. Laurentiu Picu, Prof. PhD. Habil. Mihaela Picu \\ "Dunarea de Jos" University of Galati
}

\begin{abstract}
In the case of workers performing a series of activities involving the use of equipment that transmit vibrations to the whole body, there is a risk of getting sick. In this paper, we will calculate Vibration magnitude, Partial VDV, Partial exposure, Time to reach EAV (VDV and A(8) option), Time to reach $\operatorname{ELV}(A(8)$ option only), Total VDV, Total Exposure A(8) for a worker who uses for the same operation, in 2 different days: i) forklift and lorry (from certain manufacturers), ii) same equipment (from other manufacturers). The methods of calculating daily exposure are: a) Calculation of daily exposure using partial vibration exposures and the duration of each source, b) Calculation of daily exposure using Vibration Dose Value (VDV), c) Daily exposure graph, d) Exposure points system, e) Nomogram of daily exposure, f) Methods that use the Internet. After performing all the calculations, it was found that the fastest and most accurate method is the one that uses the Internet: "Whole-body vibration exposure calculator", because it instantly gives all values of interest.
\end{abstract}

KEYWORDS: whole-body vibration, exposure action value, exposure limit value, forklift and lorry

\section{INTRODUCTION}

Nowadays there are a number of equipments used by workers, which transmit vibrations to the whole body (fig. 1) (backhoe loader, compactor - single drum, compactor tandem, dozer, dumper, dumper - articulated, excavator - wheeled, excavator $<25 \mathrm{t}$, excavator $>25 \mathrm{t}$, farm tractor, finisher/asphalt paver, forestry - forwarder, forestry - harvester, forklift truck - counter balance, fork-lift truck order pickers, fork-lift truck - reach, grader, pallet-truck - ride-on, pallet-truck - ride-on vertical, scraper, tow tractor, wheel loader, etc).

These vibrations can lead to the occurrence of specific diseases: lower-back pain and back, shoulder or neck disorders, digestive or circulatory disorders or adverse effects on the reproductive system. In some cases, an increased prevalence of gastrointestinal complaints, peptic ulcer and gastritis and injuries of the peripheral veins.

The European Union has issued Directive 2002/44/EC on the minimum health and safety requirements regarding the exposure of workers to the risks arising from physical agents (vibrations), introducing the following vibration limits transmitted to the whole body.

Daily vibration exposure can be assessed using:

1. The daily exposure, $\mathrm{A}(8)$ - the continuous equivalent acceleration, normalised to an 8 hour day, the $\mathrm{A}(8)$ value is based on rootmean-square averaging of the acceleration signal $\left(\mathrm{m} / \mathrm{s}^{2}\right)$;

2. The vibration dose value (VDV) is a cumulative dose, based on the $4^{\text {th }}$ root-meanquad of the acceleration signal $\left(\mathrm{m} / \mathrm{s}^{1.75}\right)[1]$.

- The daily exposure action value standardised to an eight-hour reference period shall be $0.5 \mathrm{~m} / \mathrm{s}^{2}$ or, at the choice of the Member State concerned, a vibration dose value of $9.1 \mathrm{~m} / \mathrm{s}^{1,75}$;

- The daily exposure limit value standardised to an eight-hour reference period shall be $1.15 \mathrm{~m} / \mathrm{s}^{2}$ or, at the choice of the Member State concerned, a vibration dose value of $21 \mathrm{~m} / \mathrm{s}^{1.75}[1]$. 
The Daily Vibration Exposure A(8) is calculated from the frequency weighted r.m.s acceleration measurements $\mathrm{a}_{\mathrm{wx}}, \mathrm{a}_{\mathrm{wy}}$, and $\mathrm{a}_{\mathrm{wz}}$ and the measured exposure period $\mathrm{T}_{\text {exp }}$. The highest value of $\mathrm{A}(8)_{\mathrm{x}}, \mathrm{A}(8)_{\mathrm{y}}$, or $\mathrm{A}(8)_{\mathrm{z}}$ is the Daily Vibration Exposure, $\mathrm{A}(8)$.

The Vibration Dose Value (VDV) provides an alternative evaluation of vibration exposure that is often used to give a better indication of the risks associated with "shock" or "peak" events. The VDV is a cumulative value that increases with measurement time. The highest value of $\mathrm{VDV}_{\text {exp }, \mathrm{x}}, \mathrm{VDV}_{\text {exp }, \mathrm{y}}$, or $\mathrm{VDV}_{\text {exp }, \mathrm{z}}$ is the Vibration Dose Value, VDV [2-4].
It is particularly important to measure the time while the worker is subjected to vibration: for example, even if the machinery is running but the worker does not operate it, this time should not be taken into consideration, or if some equipment is used only part of the day, then it cannot be stated that the worker was subjected $8 \mathrm{~h}$ to vibration [5].

Another requirement of the 2002 Directive is for the vibrating equipment manufacturer to provide information on the values of vibration emissions transmitted to the whole body.

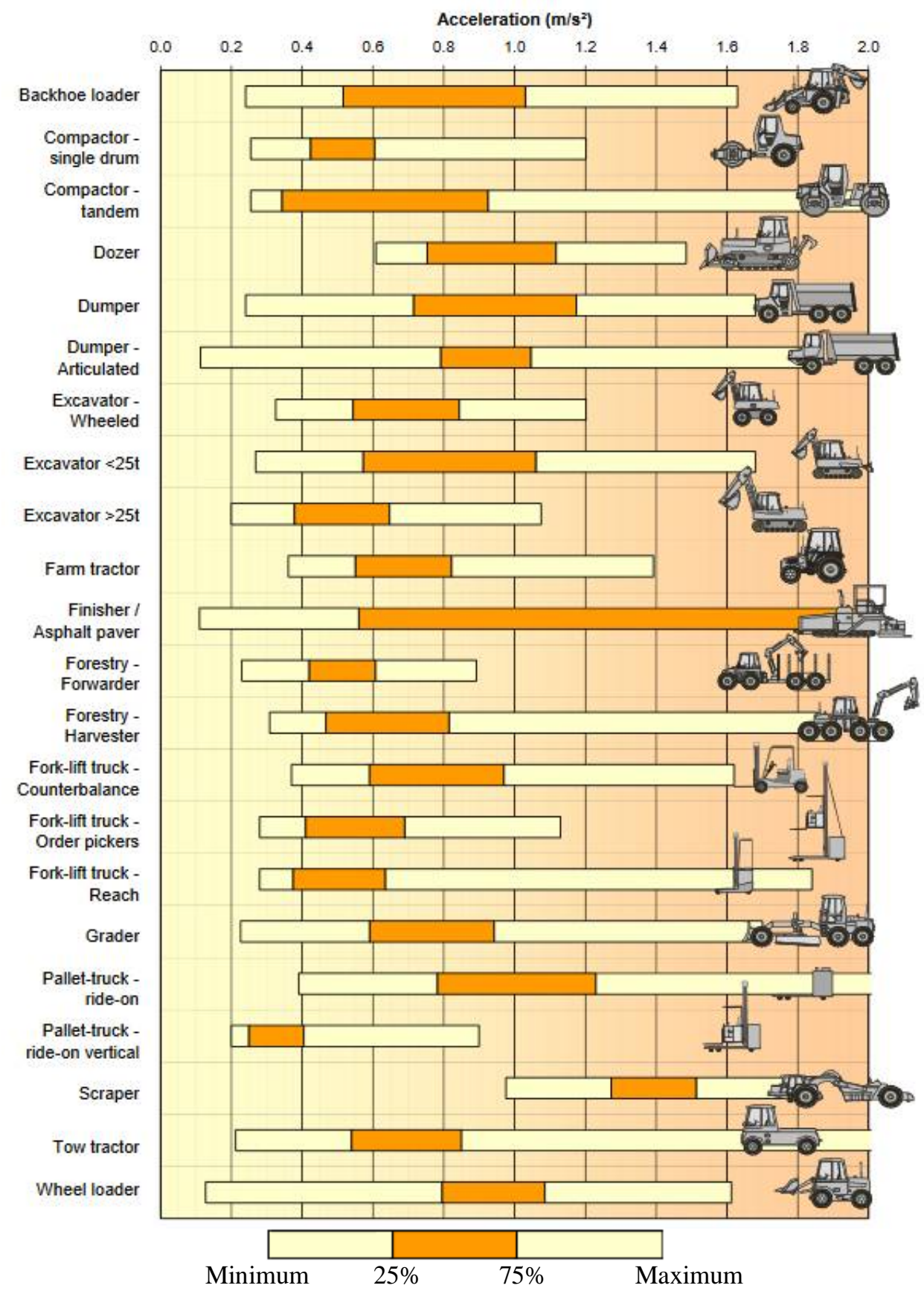

Figure 1. Examples of vibration magnitudes for common tools Ranges of vibration values for common equipment on the EU market [1]. 
Whole-body vibration magnitude is the frequency-weighted acceleration value in the highest of three orthogonal axes $\left(1.4 \mathrm{a}_{\mathrm{wx}}, 1.4 \mathrm{a}_{\mathrm{wy}}\right.$ or $\mathrm{a}_{\mathrm{wz}}$ ) for a seated or standing worker [6].

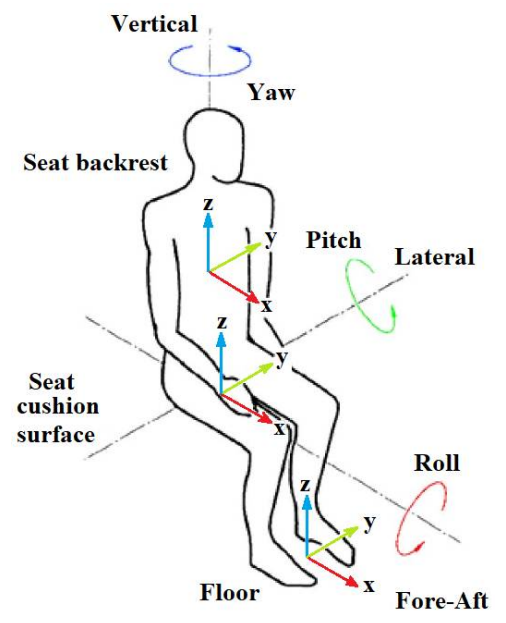

Figure 2. Definition of the seated position and coordinate systems [7]

From fig. 3 it can see that the rotation about these axes is roll, pitch, and yaw, respectively. The positive directions of the gravitoinertial forces $(G)$ along these axes are chosen to be chest-to-back $(+\mathrm{Gx})$, left-to-right $(+\mathrm{Gy})$, and head-to-foot $(+\mathrm{Gz})$, respectively. Note that the positive directions of the corresponding accelerations along these axes would be back-to-chest, right-to-left, and footto-head, respectively [8].

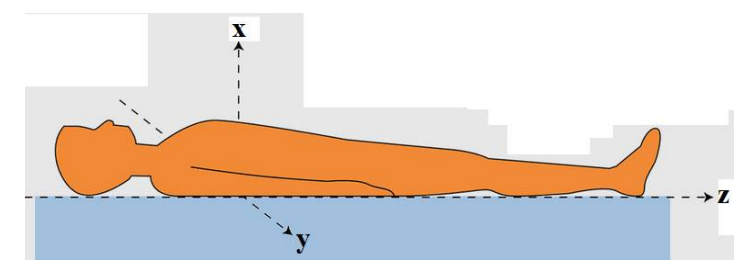

Figure 4. Definition of the recumbent position and coordinate systems

Before any calculation, the time during which a worker uses a vibrating equipment must be accurately measured, as it has been found that this time is overestimated; it is important to know if the use of that equipment is continuous or intermittent.

"For whole-body vibration, the frequencies thought to be important range from $0.5 \mathrm{~Hz}$ to $80 \mathrm{~Hz}$. However, because the risk of damage is not equal at all frequencies a frequency-weighting is used to represent the likelihood of damage from the different frequencies. As a result, the weighted acceleration decreases when the frequency increases. For whole-body vibration, two
Depending on the workers' position there are 2 main types of vibration measurement (fig. 2 and 3). In rare cases, there is also the alternative of the lying subject (fig. 4) [1].

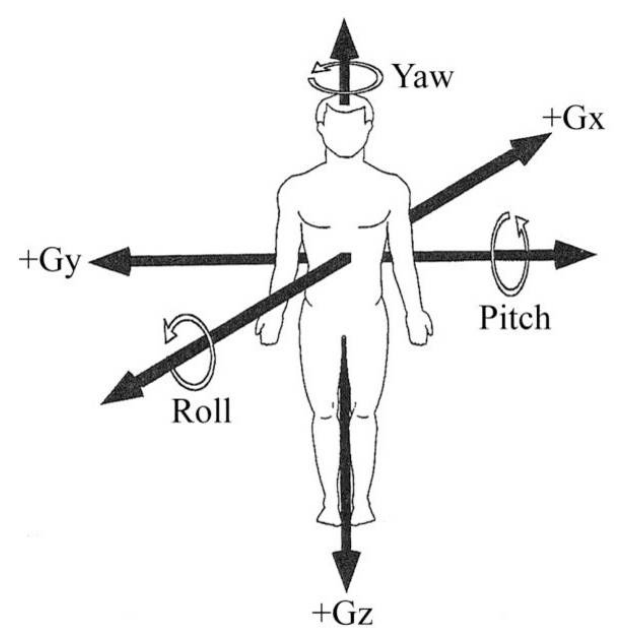

Figure 3 . The cardinal axes of the human body are defined as $\mathrm{x}, \mathrm{y}$, and $\mathrm{z}[8]$

different frequency weightings are used. One weighting (the $\mathrm{Wd}$ weighting) applies to the two lateral axes: $x$ and $y$, and another (the Wk weighting) applies to the vertical, $\mathrm{z}$-axis vibration.

When considering the risks to health from whole-body vibration an additional multiplying factor must be applied to the frequency weighted vibration values. For the two lateral axes ( $x$ and $y$ ) the acceleration values are multiplied by 1.4. For the vertical, z-axis vibration the factor is 1.0." [6].

\section{METHODS OF CALCULATING THE DAILY EXPOSURE}

There are several methods of calculating the daily exposure. Some that do the calculation directly on the internet while others that use charts, nomograms or the exposure points system [6].

In this paper, we will calculate the daily exposure for a worker who uses for the same operation, in 2 different days:

i) forklift and lorry (from certain manufacturers)

ii) same equipment (from other manufacturers).

On the first day, the worker used the equipment as follows:

1) Forklift: for $T_{1}=1$ hour and 30 minutes,

2) Lorry for $T_{2}=5$ hours and 30 minutes.

The vibration values on the seat are:

- For forklift: $\mathrm{x}$-axis: $0.6 \mathrm{~m} / \mathrm{s}^{2}$; y-axis: $0.4 \mathrm{~m} / \mathrm{s}^{2}$; z-axis: $1 \mathrm{~m} / \mathrm{s}^{2}$,

- For lorry: $\mathrm{x}$-axis: $0.3 \mathrm{~m} / \mathrm{s}^{2}$; y-axis: $0.5 \mathrm{~m} / \mathrm{s}^{2}$; z-axis: $0.6 \mathrm{~m} / \mathrm{s}^{2}$. 
On the next day, the worker used the equipment as follows:

1) Forklift: for $T_{3}=1$ hour and 45 minutes,

2) Lorry for $T_{4}=6$ hours.

The vibration values on the seat are:

For forklift: $\mathrm{x}$-axis: $0.5 \mathrm{~m} / \mathrm{s}^{2}$; $\mathrm{y}$-axis: $0.5 \mathrm{~m} / \mathrm{s}^{2}$; z-axis: $1.1 \mathrm{~m} / \mathrm{s}^{2}$,

For lorry: $\mathrm{x}$-axis: $0.2 \mathrm{~m} / \mathrm{s}^{2}$; y-axis: $0.4 \mathrm{~m} / \mathrm{s}^{2}$; $\mathrm{z}-$ axis: $0.4 \mathrm{~m} / \mathrm{s}^{2}$.

a) Calculation of daily exposure using partial vibration exposures and the duration of each source

i) for the first day: the partial vibration exposures for the two tasks are $\left(\mathrm{T}_{0}=8 \mathrm{~h}\right)$ :

1) $A_{\text {fork }}(8)_{x}=1.4 \cdot a_{x} \sqrt{\frac{T_{1}}{T_{0}}}=0.3637 \mathrm{~m} / \mathrm{s}^{2}$

2) $A_{\text {fork }}(8)_{y}=1.4 \cdot a_{y} \sqrt{\frac{T_{1}}{T_{0}}}=0.2424 \mathrm{~m} / \mathrm{s}^{2}$

3) $A_{\text {fork }}(8)_{z}=a_{z} \sqrt{\frac{T_{1}}{T_{0}}}=0.433 \mathrm{~m} / \mathrm{s}^{2}$

$A_{\text {fork }}(8)_{1}=0.7496122 \mathrm{~m} / \mathrm{s}^{2}$

4) $A_{\text {lorry }}(8)_{x}=1.4 \cdot a_{x} \sqrt{\frac{T_{2}}{T_{0}}}=0.3482 \mathrm{~m} / \mathrm{s}^{2}$

5) $A_{\text {lorry }}(8)_{y}=1.4 \cdot a_{y} \sqrt{\frac{T_{2}}{T_{0}}}=0.5804 \mathrm{~m} / \mathrm{s}^{2}$

6) $A_{\text {lorry }}(8)_{z}=a_{z} \sqrt{\frac{T_{2}}{T_{0}}}=0.4975 \mathrm{~m} / \mathrm{s}^{2}$

$A_{\text {lorry }}(8)_{1}=1.0702321 \mathrm{~m} / \mathrm{s}^{2}$

$A_{x}(8)=\left[A_{\text {fork }}(8)_{x}^{2}+A_{\text {lorry }}(8)_{x}^{2}\right]^{1 / 2}=0.5033 \mathrm{~m} / \mathrm{s}^{2}$

$A_{y}(8)=\left[A_{\text {fork }}(8)_{y}{ }^{2}+A_{\text {lorry }}(8)_{y}{ }^{2}\right]^{1 / 2}=0.6288 \mathrm{~m} / \mathrm{s}^{2}$

$A_{z}(8)=\left[A_{\text {fork }}(8)_{z}^{2}+A_{\text {lorry }}(8)_{z}^{2}\right]^{1 / 2}=0.6594 \mathrm{~m} / \mathrm{s}^{2}$

For the first day, the driver's daily whole-body vibration exposure is the highest axis $\mathrm{A}(8)$ value, in this case: $A(8)=A_{z}(8)=0.6594 \mathrm{~m} / \mathrm{s}^{2}$.

ii) for the next day: the partial vibration exposures for the two tasks are $\left(\mathrm{T}_{0}=8 \mathrm{~h}\right)$ :

7) $A_{\text {fork }}(8)_{x}=1.4 \cdot a_{x} \sqrt{\frac{T_{3}}{T_{0}}}=0.2239 \mathrm{~m} / \mathrm{s}^{2}$

8) $A_{\text {fork }}(8)_{y}=1.4 \cdot a_{y} \sqrt{\frac{T_{3}}{T_{0}}}=0.2239 \mathrm{~m} / \mathrm{s}^{2}$

9) $A_{\text {fork }}(8)_{z}=a_{z} \sqrt{\frac{T_{3}}{T_{0}}}=0.5144 \mathrm{~m} / \mathrm{s}^{2}$

$A_{\text {fork }}(8)_{2}=0.6790594 \mathrm{~m} / \mathrm{s}^{2}$

10) $A_{\text {lorry }}(8)_{x}=1.4 \cdot a_{x} \sqrt{\frac{T_{4}}{T_{0}}}=0.2424 \mathrm{~m} / \mathrm{s}^{2}$

11) $A_{\text {lorry }}(8)_{y}=1.4 \cdot a_{y} \sqrt{\frac{T_{4}}{T_{0}}}=0.4849 \mathrm{~m} / \mathrm{s}^{2}$
12) $A_{\text {lorry }}(8)_{z}=a_{z} \sqrt{\frac{T_{4}}{T_{0}}}=0.3464 \mathrm{~m} / \mathrm{s}^{2}$

$A_{\text {lorry }}(8)_{2}=0.8342716 \mathrm{~m} / \mathrm{s}^{2}$

$A_{x}(8)=\left[A_{\text {fork }}(8)_{x}{ }^{2}+A_{\text {lorry }}(8)_{x}{ }^{2}\right]^{1 / 2}=0.3298 \mathrm{~m} / \mathrm{s}^{2}$

$A_{y}(8)=\left[A_{\text {fork }}(8)_{y}{ }^{2}+A_{\text {lorry }}(8)_{y}{ }^{2}\right]^{1 / 2}=0.534 \mathrm{~m} / \mathrm{s}^{2}$

$A_{z}(8)=\left[A_{\text {fork }}(8)_{z}^{2}+A_{\text {lorry }}(8)_{z}^{2}\right]^{1 / 2}=0.6201 \mathrm{~m} / \mathrm{s}^{2}$

For the next day, the driver's daily whole-body vibration exposure is the highest axis $\mathrm{A}(8)$ value, in this case:

$A(8)=A_{z}(8)=0.6201 \mathrm{~m} / \mathrm{s}^{2}$ (fig. 5).

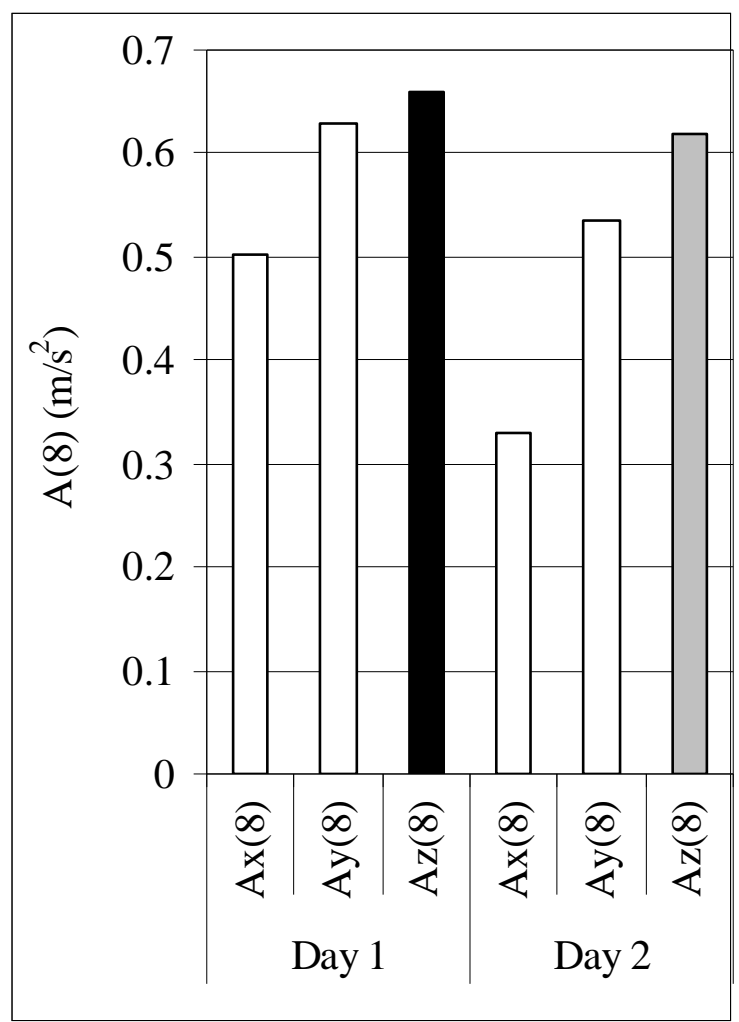

Figure 5. Comparison between the daily exposure values using partial exposures $A(8)$ ( $\square$ ) The maximum value

b) Calculation of daily exposure using Vibration Dose Value (VDV)

„Vibration Dose value shows a fourth power relationship between vibration magnitude and dose value of vibration which affects the health as well as comfort of human beings [9, 10]. VDV always accumulates for the vibration exposure and does not decay during periods of low value of vibration magnitude. As recommended by the ISO 2631 standard, daily vibration dose value (VDV) in the region of 15 $\mathrm{m} / \mathrm{s}^{1.75}$ usually causes severe discomfort and health related problems. VDV has calculated as follows:

$$
V D V=\sqrt[4]{\int_{0}^{T} a_{w}^{4}(t) d t}
$$


where $\mathrm{a}_{\mathrm{w}}$ is weighted acceleration time history and $\mathrm{T}$ is duration of the measurement" $[9,10$, 11].

i) for the first day: The vibration values on the seat, measured for 1 hour on the forklift and 3 hours on the lorry, are:

For forklift $\left\{\begin{array}{l}V D V_{x}=6.5 \mathrm{~m} / \mathrm{s}^{1.75} \\ V D V_{y}=5 \mathrm{~m} / \mathrm{s} .75 \\ V D V_{z}=14 \mathrm{~m} / \mathrm{s}^{1.75}\end{array}\right.$

The $\mathrm{x}, \mathrm{y}$ and $\mathrm{z}$ axis partial VDV are:

$V D V_{\text {exp }, x y / z, \text { fork }}=k \cdot V D V_{x / y / z, \text { for }} \cdot \sqrt[4]{\frac{T_{\text {exp }}}{T_{\text {meas }}}}$

where: $\mathrm{T}_{\exp }=1.5 \mathrm{~h}$ and $\mathrm{T}_{\text {meas }}=1 \mathrm{~h}$

so: $\sqrt[4]{\frac{T_{\text {exp }}}{T_{\text {meas }}}}=\sqrt[4]{\frac{1.5}{1}}=1.1066$

$V D V_{\text {exp } x, \text { fork }}=1.4 \cdot 6.5 \cdot 1.1066=10.0708 \mathrm{~m} / \mathrm{s}^{1.75}$

$V D V_{\text {exp }, y, \text { fork }}=1.4 \cdot 5 \cdot 1.1066=7.7467 \mathrm{~m} / \mathrm{s}^{1.75}$

$V D V_{\text {exp }, \text { fork }}=1 \cdot 14 \cdot 1.1066=15.4924 \mathrm{~m} / \mathrm{s}^{1.75}$

For lorry $\left\{\begin{array}{l}V D V_{x}=3 \mathrm{~m} / \mathrm{s}^{1.75} \\ V D V_{y}=4.5 \mathrm{~m} / \mathrm{s}^{1.75} \\ V D V_{z}=6.5 \mathrm{~m} / \mathrm{s}^{1.75}\end{array}\right.$

where: $\mathrm{T}_{\text {exp }}=5.5 \mathrm{~h}$ and $\mathrm{T}_{\text {meas }}=3 \mathrm{~h}$

so: $\sqrt[4]{\frac{T_{\text {exp }}}{T_{\text {meas }}}}=\sqrt[4]{\frac{5.5}{3}}=1.1636$

$V D V_{\text {exp }, x, \text { lorry }}=1.4 \cdot 3 \cdot 1.1636=4.8871 \mathrm{~m} / \mathrm{s}^{1.75}$

$V D V_{\text {exp,y, lorry }}=1.4 \cdot 4.5 \cdot 1.1636=7.3306 \mathrm{~m} / \mathrm{s}^{1.75}$

$V D V_{\text {exp, } z \text {, lorry }}=1 \cdot 6.5 \cdot 1.1636=7.5634 \mathrm{~m} / \mathrm{s}^{1.75}$

For the first day, the highest exposure was $V D V_{\text {exp }, z, \text { fork }}=15.4924 \mathrm{~m} / \mathrm{s}^{1.75}$

ii) for the next day: The vibration values on the seat, measured for the same time periods as on the first day:

For forklift $\left\{\begin{array}{l}V D V_{x}=5.8 m / s^{1.75} \\ V D V_{y}=5.6 m / s^{1.75} \\ V D V_{z}=15.5 m / s^{1.75}\end{array}\right.$

The $\mathrm{x}, \mathrm{y}$ and $\mathrm{z}$ axis partial VDV are:

$V D V_{\text {exp } x / y / z \text {, fork }}=k \cdot V D V_{x / y / z \text { fork }} \cdot \sqrt[4]{\frac{T_{\text {exp }}}{T_{\text {meas }}}}$

where: $\mathrm{T}_{\exp }=1.75 \mathrm{~h}$ and $\mathrm{T}_{\text {meas }}=1 \mathrm{~h}$

so: $\sqrt[4]{\frac{T_{\text {exp }}}{T_{\text {meas }}}}=\sqrt[4]{\frac{1.75}{1}}=1.1501$

$V D V_{\text {exp }, x, \text { fork }}=1.4 \cdot 5.8 \cdot 1.1501=10.0058 \mathrm{~m} / \mathrm{s}^{1.75}$

$V D V_{\text {exp }, y, \text { fork }}=1.4 \cdot 5.6 \cdot 1.1501=9.0167 \mathrm{~m} / \mathrm{s}^{1.75}$

$V D V_{\text {exp }, \text { fork }}=1 \cdot 15.5 \cdot 1.1501=17.8265 \mathrm{~m} / \mathrm{s}^{1.75}$
For lorry $\left\{\begin{array}{l}V D V_{x}=2.7 m / s^{1.75} \\ V D V_{y}=4.2 m / s^{1.75} \\ V D V_{z}=5.8 m / s\end{array}\right.$

where: $\mathrm{T}_{\text {exp }}=6 \mathrm{~h}$ and $\mathrm{T}_{\text {meas }}=3 \mathrm{~h}$

so: $\sqrt[4]{\frac{T_{\text {exp }}}{T_{\text {meas }}}}=\sqrt[4]{\frac{6}{3}}=1.1892$

$V D V_{\text {exp }, \text {, lorry }}=1.4 \cdot 2.7 \cdot 1.1892=4.4951 \mathrm{~m} / \mathrm{s}^{1.75}$

$V D V_{\text {exp,y, lorry }}=1.4 \cdot 4.2 \cdot 1.1892=6.9924 \mathrm{~m} / \mathrm{s}^{1.75}$

$V D V_{\text {exp }, z \text {, lorry }}=1 \cdot 5.8 \cdot 1.1892=6.8973 \mathrm{~m} / \mathrm{s}^{1.75}$

For the second day, the highest exposure was $V D V_{\text {exp, } z \text {, fork }}=17.8265 \mathrm{~m} / \mathrm{s}^{1.75}$ (fig. 6).

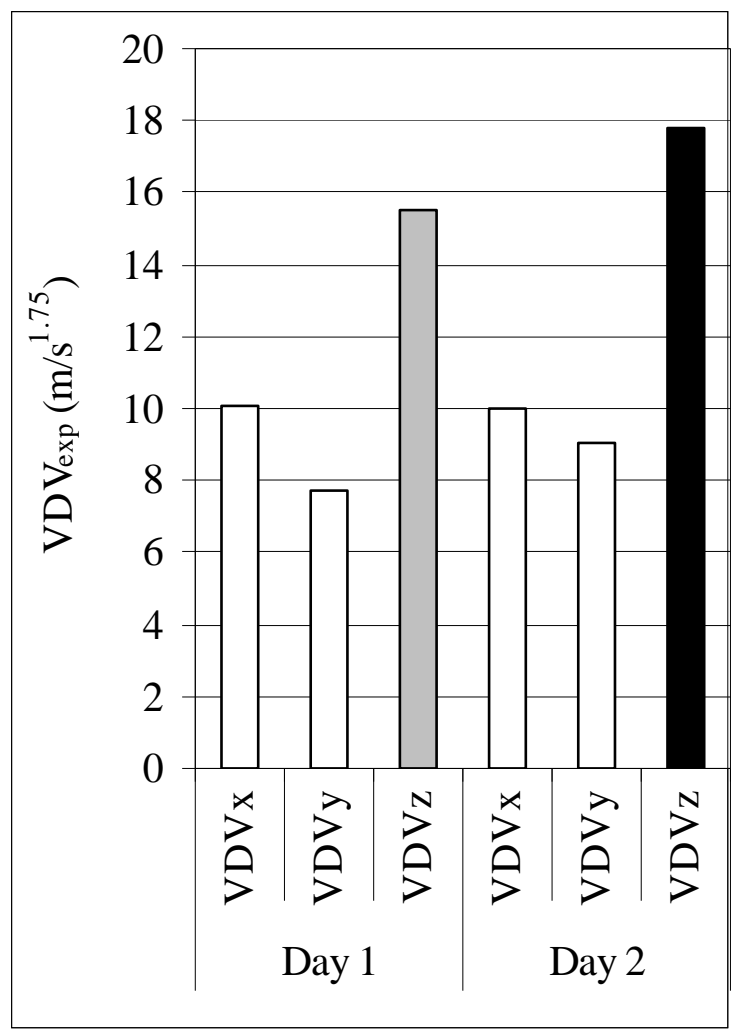

Figure 6. Comparison between the daily exposure values using Vibration Dose Value (VDV) (匹) The maximum value

c) Daily exposure graph

To be able to observe quickly, but with a certain approximation, which a workers' daily exposure to the vibrations generated by a particular equipment, it is sufficient to unite the line that rises from the horizontal axis (exposure time) with the one that rises from the vertical axis (vibration magnitude) and find out in which area they intersect. Starting from this area toward the right vertical axis, one can find the value $A(8)$. For the 2 studied cases (fig. 7) it is noted that:

- for day 1: the intersection of the red lines occurs at approximately $A_{1}(8)=0.63 \mathrm{~m} / \mathrm{s}^{2}$ 
- for day 2: the intersection of the red lines occurs at approximately $\mathrm{A}_{2}(8)=0.61 \mathrm{~m} / \mathrm{s}^{2}$

Here too, is seen that $A_{1}(8)$ and $A_{2}(8)$ are in the white area.

d) Exposure points system

Another relatively simple method for analysing vibrations transmitted to the wholebody system is to calculate the number of exposure points accumulated in an hour $\left(\mathrm{P}_{\mathrm{E}, 1 \mathrm{~h}}\right.$ in points per hour):

$$
P_{E, l h}=50\left(k \cdot a_{w}\right)^{2}
$$

where factor $\mathrm{k}=1.4$ (for $\mathrm{x} / \mathrm{y}-$ axes) and $\mathrm{k}=1$ (for $\mathrm{z}-$ axes) and $\mathrm{a}_{\mathrm{w}}$ is the vibration magnitude.
The exposure scores corresponding to the exposure action and limit values are:

i) exposure action value $\left(0.5 \mathrm{~m} / \mathrm{s}^{2}\right)=100$ points;

ii) exposure limit value $\left(1.15 \mathrm{~m} / \mathrm{s}^{2}\right)=529$ points.

The number of exposure points:

$$
P_{E}=\left(\frac{k \cdot a_{w}}{0.5 m / s^{2}}\right)^{2} \cdot \frac{T}{8 h} \cdot 100
$$

where $\mathrm{T}$ is the exposure time $(\mathrm{h})$.

And vice versa:

$$
A(8)=0.5 \mathrm{~m} / \mathrm{s}^{2} \cdot \sqrt{\frac{P_{E}}{100}}
$$

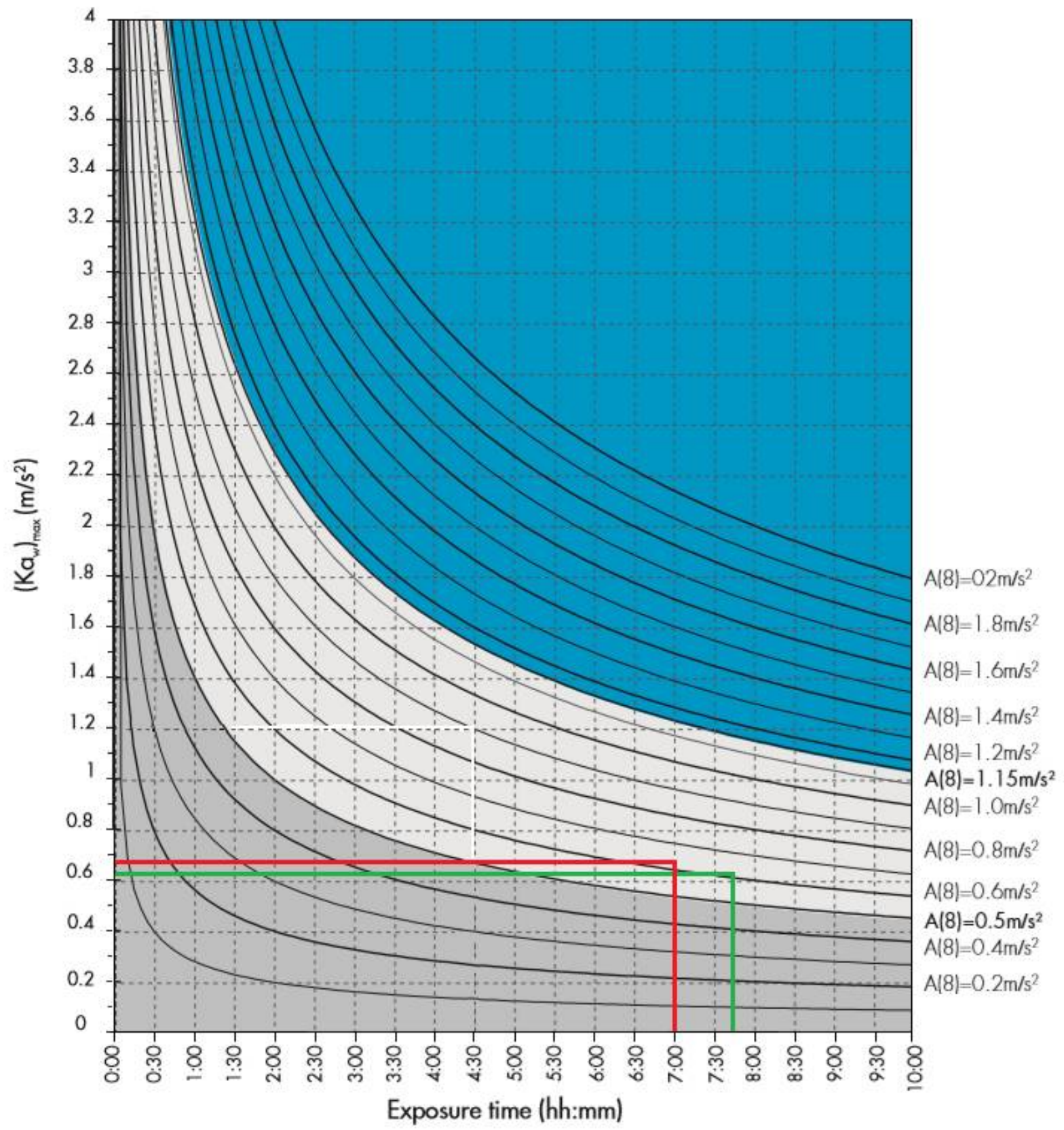

Figure 7. Daily exposure graph [6]

the red line corresponds to day 1 ; the green line corresponds to day 2 


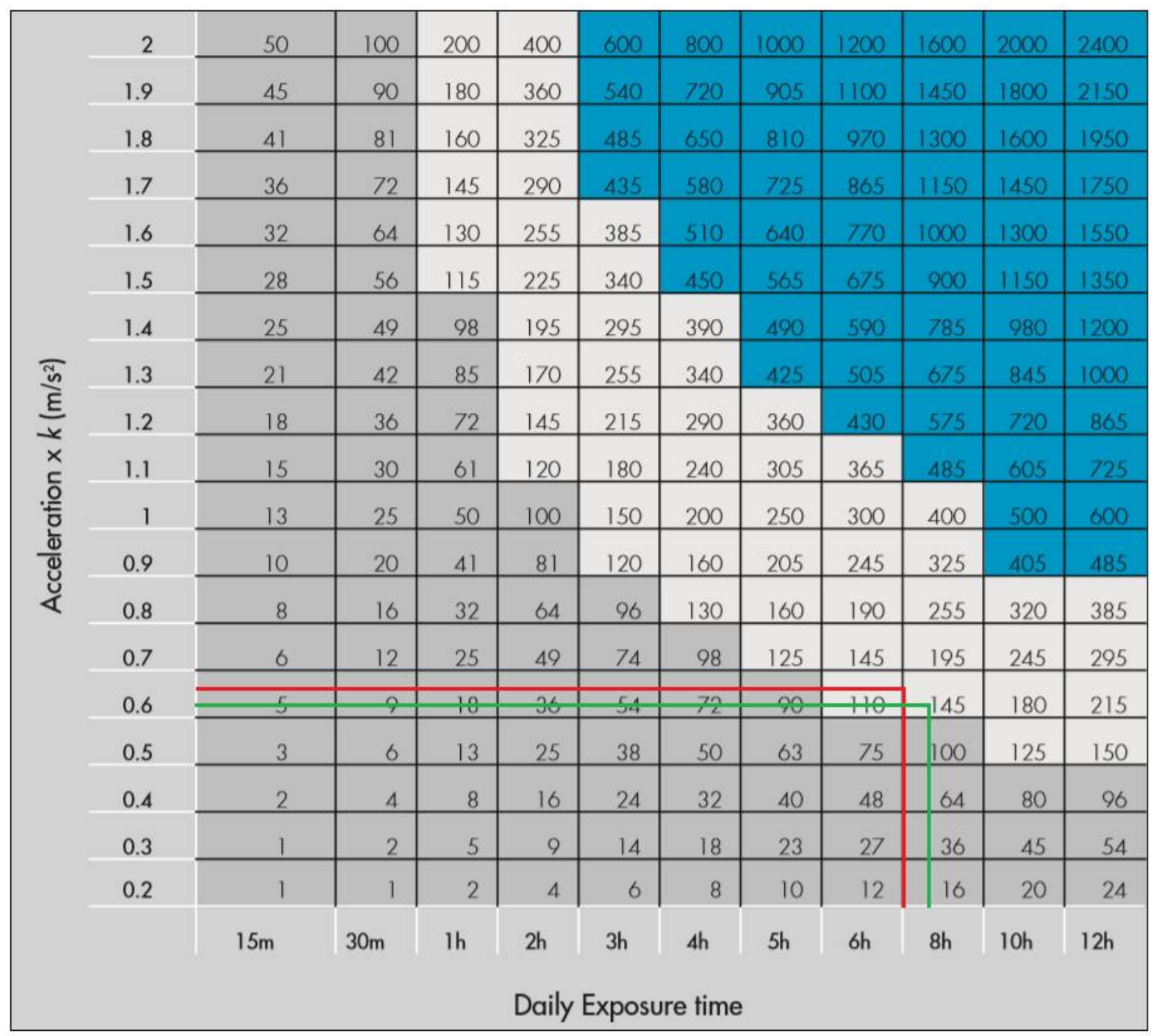

Figure 8. Exposure points table (rounded values) [6]

From figure 8 it is seen that for day 1 (red line), the intersection occurs at about 138 points, and for day 2 (green line), at about 144 points. By doing the reverse calculation, we obtain:

$A_{l}(8)=0.5 \cdot \sqrt{\frac{138}{100}}=0.5873 \mathrm{~m} / \mathrm{s}^{2}$ (relatively into $\left.\mathrm{A}(8)=0.5916 \mathrm{~m} / \mathrm{s}^{2}\right)$

$A_{2}(8)=0.5 \cdot \sqrt{\frac{144}{100}}=0.6 \mathrm{~m} / \mathrm{s}^{2}$ (relatively into $\mathrm{A}(8)$ $=0.6201 \mathrm{~m} / \mathrm{s}^{2}$ )

so the results are relatively close.

e) Nomogram of daily exposure

On the nomogram in figure 9 (representing day 1) is drawn a line that unites the magnitude of the vibration with the exposure time. From the intersection with the middle line, one can obtain the partial exposures:

- Thin red lines:
For the line $1 \times \mathrm{A}_{\text {fork, }}(8)_{\mathrm{x}}$, the intersection occurs at approximately $0.36 \mathrm{~m} / \mathrm{s}^{2}$,

For the line $1 \mathrm{y} \mathrm{A}_{\text {fork }}(8)_{\mathrm{y}}$, the intersection occurs at approximately $0.25 \mathrm{~m} / \mathrm{s}^{2}$,

For the line $1 \mathrm{z} \mathrm{A}_{\text {fork }}(8)_{\mathrm{z}}$, the intersection occurs at approximately $0.43 \mathrm{~m} / \mathrm{s}^{2}$.

- Thick red lines:

For the line $2 \mathrm{x} \mathrm{A}_{\text {lorry }}(8)_{\mathrm{x}}$, the intersection occurs at approximately $0.35 \mathrm{~m} / \mathrm{s}^{2}$,

For the line $2 \mathrm{y} \mathrm{A}_{\text {lorry }}(8) \mathrm{y}$, the intersection occurs at approximately $0.58 \mathrm{~m} / \mathrm{s}^{2}$,

For the line $2 \mathrm{z} \quad \mathrm{A}_{\text {lorry }}(8) \mathrm{z}$, the intersection occurs at approximately $0.5 \mathrm{~m} / \mathrm{s}^{2}$.

From the nomogram presented in figure 10 (representing day 2), results:

- Thin blue lines:

For the line $3 \mathrm{x} \mathrm{A}_{\text {fork }}(8)_{, \mathrm{x}}$, the intersection occurs at approximately $0.33 \mathrm{~m} / \mathrm{s}^{2}$,

For the line $3 \mathrm{y}_{\text {fork }}(8)_{\mathrm{y}}$, the intersection occurs at approximately $0.33 \mathrm{~m} / \mathrm{s}^{2}$,

For the line $3 \mathrm{z} \mathrm{A}_{\text {fork }}(8)_{\mathrm{z}}$, the intersection occurs at approximately $0.5 \mathrm{~m} / \mathrm{s}^{2}$. 


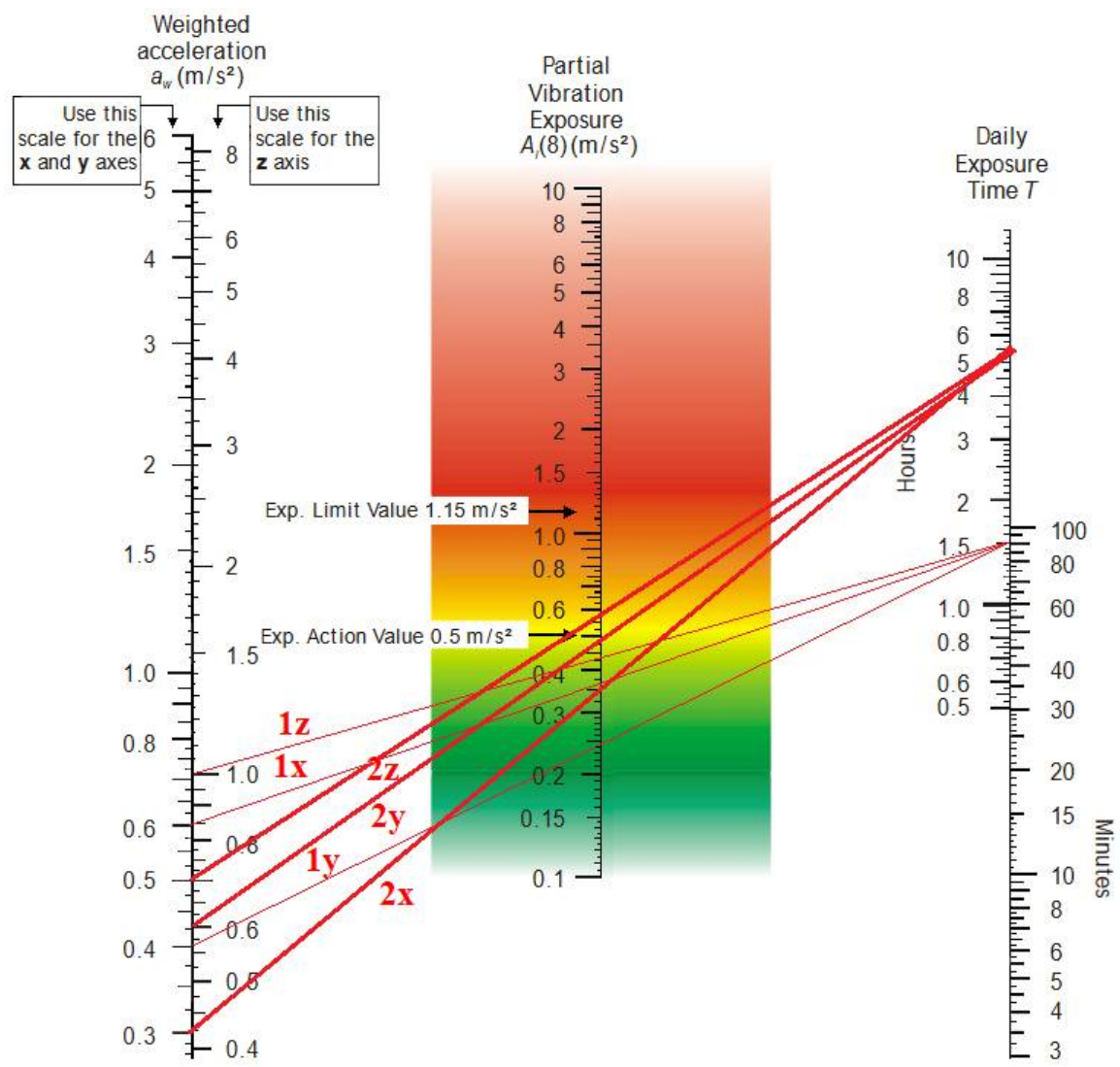

Figure 9. The nomogram of daily exposure of the WBV on the first day

(-) Thin red lines correspond to forklift; (-) Thick red lines correspond to lorry

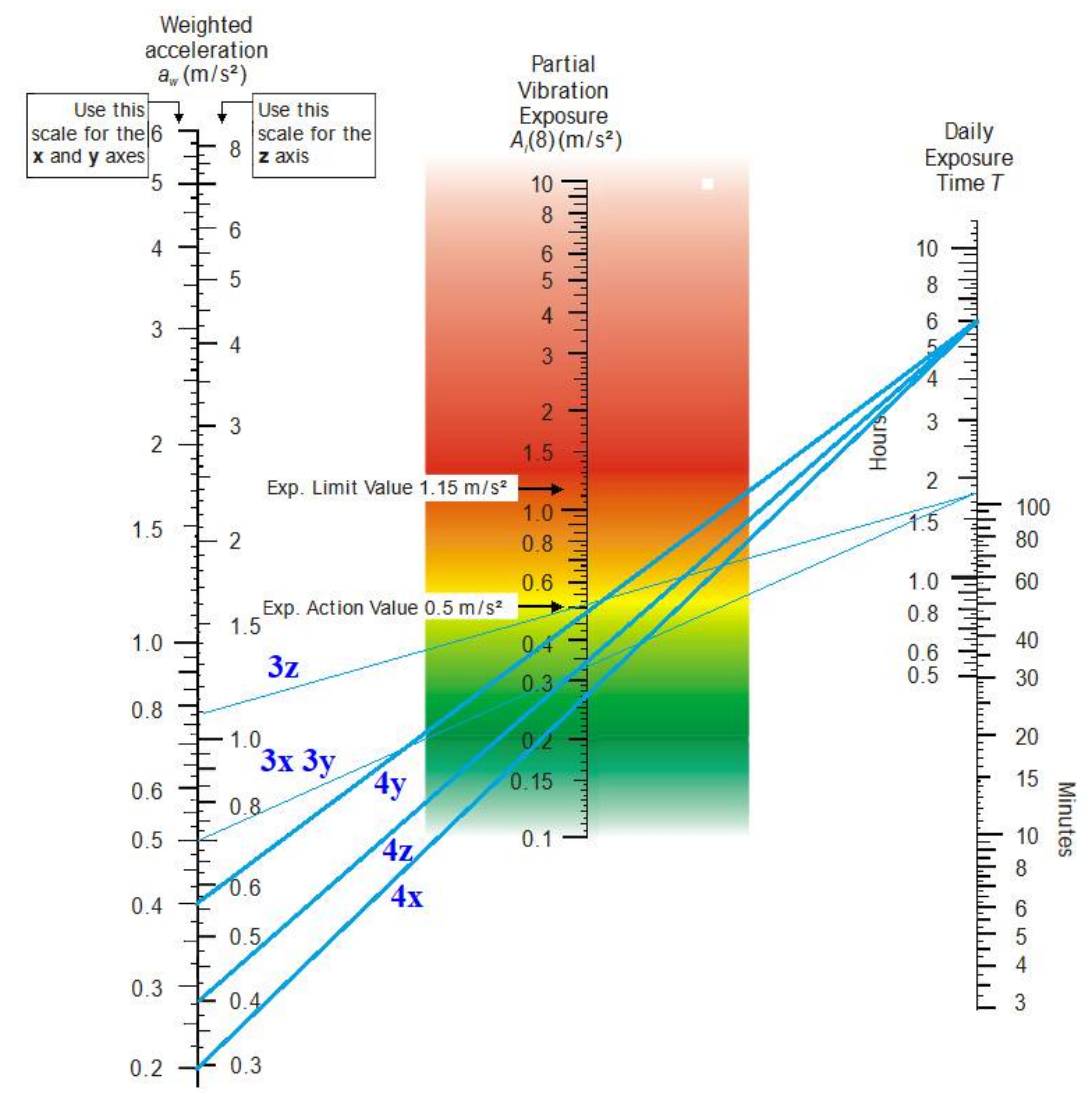

Figure 10. The nomogram of daily exposure of the WBV on the second day (一) The thin blue lines correspond to the forklift; (-) Thick blue lines correspond to lorry 
- Thick blue lines:

For the line $4 \mathrm{x} \mathrm{A}_{\text {lorry }}(8)_{\mathrm{x}}$, the intersection occurs at approximately $0.27 \mathrm{~m} / \mathrm{s}^{2}$,

For the line $4 \mathrm{y} \mathrm{A}_{\text {lorry }}(8)_{\mathrm{y}}$, the intersection occurs at approximately $0.35 \mathrm{~m} / \mathrm{s}^{2}$,

For the line $4 \mathrm{z} \mathrm{A}_{\text {lorry }}(8)_{\mathrm{z}}$, the intersection occurs at approximately $0.49 \mathrm{~m} / \mathrm{s}^{2}$.
Comparing the calculations in point a) and those in point $\mathrm{e}$ ), it is seen that large differences occur on day 2 , when measuring on the $x$ and $y$ axes (Table 1): the values read on the nomogram are $47.38 \%$ higher than those calculated using partial vibration exposures and the duration of each source.

Table 1. Calculation of daily exposure using:

\begin{tabular}{|c|c|c|c|c|c|c|c|c|c|c|c|c|}
\hline & \multicolumn{6}{|c|}{ Day 1} & \multicolumn{6}{|c|}{ Day 2} \\
\hline & \multicolumn{3}{|c|}{$\begin{array}{c}\text { Partial vibration } \\
\text { exposures and the } \\
\text { duration of each source }\end{array}$} & \multicolumn{3}{|c|}{$\begin{array}{c}\text { Nomogram of daily } \\
\text { exposure }\end{array}$} & \multicolumn{3}{|c|}{$\begin{array}{c}\text { Partial vibration } \\
\text { exposures and the } \\
\text { duration of each source }\end{array}$} & \multicolumn{3}{|c|}{$\begin{array}{l}\text { Nomogram of daily } \\
\text { exposure }\end{array}$} \\
\hline & $\mathrm{X}$ & $\mathrm{y}$ & $z$ & $\mathrm{X}$ & $\mathrm{y}$ & $\mathrm{Z}$ & $\mathrm{X}$ & $\mathrm{y}$ & $\mathrm{Z}$ & $\mathrm{X}$ & $\mathrm{y}$ & $\mathrm{Z}$ \\
\hline fork & 0.3637 & 0.2424 & 0.433 & 0.36 & 0.25 & 0.43 & 0.2239 & 0.2239 & 0.5144 & 0.33 & 0.33 & 0.5 \\
\hline lorry & 0.3482 & 0.5804 & 0.4975 & 0.35 & 0.58 & 0.5 & 0.2424 & 0.4849 & 0.3464 & 0.27 & 0.49 & 0.35 \\
\hline
\end{tabular}

\begin{tabular}{|c|c|c|c|c|c|c|c|}
\hline \multicolumn{2}{|c|}{ 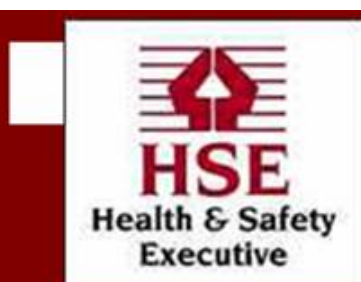 } & \multicolumn{6}{|c|}{ Daily Vibration Exposure A(8) } \\
\hline \multirow{3}{*}{ Day 1} & \multirow{3}{*}{\begin{tabular}{|l|}
$\begin{array}{l}\text { Vibration } \\
\text { magnitude }\end{array}$ \\
$\mathrm{m} / \mathrm{s}^{2}$ r.m.s. \\
\end{tabular}} & \multicolumn{6}{|c|}{$\sqrt{ } \mathrm{K}$-factor included in input values } \\
\hline & & \multicolumn{2}{|c|}{$\begin{array}{l}\text { Exposure } \\
\text { duration }\end{array}$} & \multirow{2}{*}{ Day 2} & \multirow{2}{*}{\begin{tabular}{c|}
$\begin{array}{c}\text { Vibration } \\
\text { magnitude }\end{array}$ \\
$\mathrm{m} / \mathrm{s}^{2}$ r.m.s. \\
\end{tabular}} & \multicolumn{2}{|c|}{$\begin{array}{l}\text { Exposure } \\
\text { duration }\end{array}$} \\
\hline & & hours & minutes & & & hours & minutes \\
\hline forklift & 0.7496122 & 1 & 30 & forklift & 0.6790594 & 1 & 45 \\
\hline Iorry & 1.0702321 & 5 & 30 & Iorry & 0.8342716 & 6 & \\
\hline \multicolumn{2}{|c|}{$\begin{array}{l}\text { Partial VDV } \\
\mathrm{m} / \mathrm{s}^{1.75}\end{array}$} & \multicolumn{2}{|c|}{$\begin{array}{l}\text { Partial exposure } \\
\mathrm{m} / \mathrm{s}^{2} A(8)\end{array}$} & \multicolumn{2}{|c|}{$\begin{array}{l}\text { Partial VDV } \\
\mathrm{m} / \mathrm{s}^{1.75}\end{array}$} & \multicolumn{2}{|c|}{$\begin{array}{l}\text { Partial exposure } \\
\mathrm{m} / \mathrm{s}^{2} A(8)\end{array}$} \\
\hline \multicolumn{2}{|c|}{8.99628} & \multicolumn{2}{|c|}{0.32} & \multicolumn{2}{|c|}{8.46976} & \multicolumn{2}{|c|}{0.32} \\
\hline \multicolumn{2}{|c|}{17.7735} & \multicolumn{2}{|c|}{0.89} & \multicolumn{2}{|c|}{14.1595} & \multicolumn{2}{|c|}{0.72} \\
\hline \multicolumn{2}{|c|}{$\begin{array}{c}\text { Time to reach EAV } \\
\text { (VDV option) } \\
9.1 \mathrm{~m} / \mathrm{s}^{1.75} \mathrm{VDV}\end{array}$} & \multicolumn{2}{|c|}{$\begin{array}{c}\text { Time to reach EAV } \\
(A(8) \text { option) } \\
0.5 \mathrm{~m} / \mathrm{s}^{2} A(8\end{array}$} & \multicolumn{2}{|c|}{$\begin{array}{c}\text { Time to reach EAV } \\
\text { (VDV option) } \\
9.1 \mathrm{~m} / \mathrm{s}^{1.75} \mathrm{VDV}\end{array}$} & \multicolumn{2}{|c|}{$\begin{array}{c}\text { Time to reach EAV } \\
(A(8) \text { option }) \\
0.5 \mathrm{~m} / \mathrm{s}^{2} A(8\end{array}$} \\
\hline hours & minutes & hours & minutes & hours & minutes & hours & minutes \\
\hline 1 & 10 & 3 & 34 & 2 & 10 & 4 & 20 \\
\hline 0 & 23 & 1 & 45 & 1 & 1 & 2 & 52 \\
\hline \multicolumn{2}{|c|}{$\begin{array}{c}\text { Time to reach ELV } \\
(\mathrm{A}(8) \text { option only) } \\
1.15 \mathrm{~m} / \mathrm{s}^{2} A(8)\end{array}$} & $\begin{array}{l}\text { Total } \\
\text { VDV } \\
\mathrm{m} / \mathrm{s}^{1.75}\end{array}$ & \begin{tabular}{|c|} 
Total \\
exposure \\
$\mathrm{m} / \mathrm{s}^{2} A(8)$ \\
\end{tabular} & \multicolumn{2}{|c|}{$\begin{array}{c}\text { Time to reach ELV } \\
\text { (A(8) option only) } \\
1.15 \mathrm{~m} / \mathrm{s}^{2} A(8)\end{array}$} & $\begin{array}{l}\text { Total } \\
\text { VDV } \\
\mathrm{m} / \mathrm{s}^{1.75}\end{array}$ & $\begin{array}{c}\text { Total } \\
\text { exposure } \\
\mathrm{m} / \mathrm{s}^{2} A(8) \\
\end{array}$ \\
\hline hours & minutes & 18.058216 & 0.944892 & hours & minutes & 14.592457 & 0.789226 \\
\hline 18 & 50 & & & 22 & 57 & & \\
\hline 9 & 14 & & & 15 & 12 & & \\
\hline
\end{tabular}

Figure 11. Whole-body vibration exposure calculator for day 1 and 2 
f) Methods that use the Internet

In order to quickly and accurately assess the degree of exposure to WBV, the "Whole body vibration Calculator" was developed. Operation description name, vibration magnitude and exposure duration are introduced in this computer; it will calculate the exposure points/hour, time to rich $\operatorname{EAV}\left(2.5 \mathrm{~m} / \mathrm{s}^{2}\right)$ and time to rich $\operatorname{ELV}\left(5 \mathrm{~m} / \mathrm{s}^{2}\right)$, as well as partial exposure (in $\mathrm{m} / \mathrm{s}^{2}$ and points). In this way one can quickly find daily exposure (in $\mathrm{m} / \mathrm{s}^{2}$ and points). For the presented cases, the calculation is (fig. 11).

\section{CONCLUSIONS}

To find out which method is most accurate, a parallel will be drawn between the results obtained with methods $\mathrm{c}$ and $\mathrm{d}$, as compared to the first method a (Table 2).

Table 2. Parallel between 3 calculation methods for daily whole-body vibration exposure

\begin{tabular}{|c|c|c|c|c|c|}
\hline \multicolumn{3}{|c|}{ Day 1- $\mathrm{A}_{1}(8)$} & \multicolumn{3}{c|}{ Day 2- $\mathrm{A}_{2}(8)$} \\
\hline \multicolumn{3}{|c|}{ Method } & \multicolumn{3}{c|}{ Method } \\
\hline $\mathrm{a}$ & $\mathrm{c}$ & $\mathrm{d}$ & $\mathrm{a}$ & $\mathrm{c}$ & $\mathrm{d}$ \\
\hline 0.6594 & 0.63 & 0.5873 & 0.6201 & 0.61 & 0.6 \\
\hline$\%$ & $<4.45$ & $<10.93$ & $\%$ & $<1.62$ & $<3.24$ \\
\hline
\end{tabular}

It can be seen that the largest deviation is the daily whole-body vibration exposure from day 1 , when is used the exposure point system method $(<10.93)$. Usually, the methods that use graphical means are highly subjected to human errors because they depend on each person ability to draw, respectively to assess the objective physical values.

The fastest and most accurate method is the one using the "Whole body vibration Calculator", as it offers ready-made calculations for all values that characterize WBV.

\section{REFERENCES}

[1] Directive 2002/44/EC of the European Parliament and of the Council of 25 June 2002 on the minimum health and safety requirements regarding the exposure of workers to the risks arising from physical agents (vibration)

[2] Larson Davis - a PCB Piezotronics division, Understanding Whole-Body Vibration, http://www.larsondavis.com/applications/hvm/whole-bodyvibration, (accessed March 11, 2020)

[3] EN 1032:2003, Mechanical vibration - Testing of mobile machinery in order to determine the vibration emission value

[4] EN 12096:1997, Mechanical vibration - Declaration and verification of vibration emission values

[5] EN 14253:2003, Mechanical vibration. Measurement and calculation of occupational exposure to whole-body vibration with reference to health. Practical guidance

[6] Non-binding guide to good practice with a view to implementation of Directive 2002/44/EC on the minimum health and safety requirements regarding the exposure of workers to the risks arising from physical agents (vibrations), 2009

[7] Coyte, J., Stirling, D., Ros, M., Seated Whole-Body Vibration Analysis, Technologies, and Modeling: A Survey, IEEE Transactions on Systems, Man, and Cybernetics: Systems, Vol. 46, Issue: 6, June 2016, pp 725-739

[8] Clément, G, Bukley, A., Artificial Gravity, Microbial Ecology 47, pp 119-126, 2007

[9] Griffin, M.J., Handbook of Human vibration, Elsevier Academic Press, 1990

[10] Mansfield, N.J., Handbook of Human Response to Vibration, CRC Press, 2005

[11] Kumar, V., Saran, V.H., Guruguntl, V., Study of Vibration Dose Value and Discomfort due to Whole Body Vibration Exposure for a Two Wheeler Drive, Proceedings of the $1^{\text {st }}$ International and $16^{\text {th }}$ National Conference on Machines and Mechanisms, IIT Roorkee, India, Dec 18-20 2013, pp. 947-952 . 